Muñoz, A. E. (2017). Evaluación económica y social de cuatro municipios liderados por alcaldesas en el departamento del Chocó. Revista Lebret, 9. Bucaramanga, Colombia: Universidad Santo Tomás. pp 99-117 - ISSN Versión Impresa: 2145-5996 - ISSN Versión Web On-line: 2357-5468 • http://dx.doi. org/10.15332/rl.v0i9.1952

\title{
Evaluación económica y social de cuatro municipios liderados por alcaldesas en el departamento del Chocó*
}

\section{Economic and social evaluation of four municipalities led by mayors in the department of Chocó}

Ángel Emilio Muñoz Cardona

\begin{abstract}
Resumen
Después de 28 años de comicios regionales en Colombia $^{2}$, la mujer del departamento del Chocó, entre el 2012 y el 2016, ganó siete alcaldías. La población del Chocó está conformada por minorías étnicas -negras e indígenas-, victimizadas por la violencia de Estado y el machismo; lo que motivó las preguntas de investigación: ¿cuál ha sido el alcance de los gobiernos de la mujer en la reducción de la violencia de género y de Estado? ¿Qué se ha hecho para reducir la feminización de la pobreza y el machismo en dichos territorios? La metodología de investigación es deductiva, realizada a través de encuestas directas a líderes de organizaciones sociales y comunales y de verificación directa a la información suministrada. El estudio concluye que es difícil lograr grandes cambios culturales en lo político y en lo familiar en cuatro años o menos de gobierno; y sobre todo, cuando es urgente pensar nuevas formas de elección popular, que aminore la corrupción y sean más importantes los programas de Gobierno y de planes de desarrollo.
\end{abstract}

\section{Palabras clave}

Violencia de Estado, violencia de género, elección popular, equidad de género, acción social comunicativa.

Códigos de clasificación JEL: D63, I31, J16, 021

\begin{abstract}
After 28 years of regional elections in Colombia, the women of the Department of Chocó, between 2012 and 2016 won seven mayoralties. The population of Chocó are made up of ethnic minorities -black and indigenous- victimized by state violence and machismo; which motivated the research questions: What has been the scope of the governments of the woman in the reduction of the violence of gender and of State? What have they been done to reduce the feminization of poverty and machismo in these territories? The research methodology is deductive, taken through direct surveys of leaders of social and communal organizations and direct verification of the information provided. The study concludes that it is difficult to achieve great cultural changes in the political and in the family in four years or less of government; and above all, when it is urgent to think of new forms of popular election, to reduce corruption and Government Plans become more important.
\end{abstract}

\section{Keywords}

State violence, gender violence, popular choice, gender equity, communicative social action.

* Artículo derivado de la investigación "Políticas públicas de dignidad de género para la mujer negra colombiana", del grupo Gobierno, Territorio y Cultura, de la Escuela Superior de Administración Pública.

1 Posdoctorado Public Economics. Docente investigador, vinculado al grupo de investigación Gobierno, Territorio y Cultura de la Escuela Superior de Administración Pública, Medellín, Colombia. Correo electrónico: angel@ esap.gov.co

2 En Colombia, los comicios electorales regionales se dan con el Acto Legislativo 01 de 1986 para alcaldes y en la reforma a la Constitución Política Nacional de 1991 en el artículo 303 para gobernadores. 


\section{Introducción}

Colombia es un país multicultural con minorías negras e indígenas, con diferencias culturales bien acentuadas (Muñoz, 2017). Más allá de las diferencias culturales existentes, prima el común denominador de ser pobres, victimizadas por el narcotráfico y grupos al margen de la ley; son poblaciones que adolecen de servicios públicos básicos del Estado ${ }^{3}$, sin un sector de economía empresarial fuerte y donde la principal fuente de empleo la ofrece la administración pública municipal -Alcaldía, banco del Gobierno, escuelas y colegios, centros médicos hospitalarios, Fiscalía, Inspección de Policía y Comisaría de Familia-; instituciones oficiales utilizadas por los partidos políticos que centralizan las decisiones de contratación y de empleo en pago de favores, lo que en palabras de Acemoglu y Robinson (2012, pp. 63-85; 225) llaman consolidación de instituciones extractivas, realidades sociopolíticas de abandono que las empobrecen.

El departamento del Chocó está conformado por 30 municipios, con un $80 \%$ de población negra, un $12 \%$ de población indígena y un $8 \%$ de población mestiza. Ubicado en las riberas del océano pacífico, lo que lo hace poseedor de amplias riquezas marítimas, pesqueras y turísticas en: Bahía Solano, Trigana, Capurganá, Nuquí, Acandí y el Parque Nacional los Katíos. A pesar de estás riquezas naturales y turísticas ningún municipio del Chocó cuenta con todos los servicios básicos del Estado -acueducto, alcantarillado, salubridad, gas, hospitales, internet, vías y aceras pavimentadas-, no poseen pequeñas, medianas y grandes empresas nacionales. La economía gira alrededor de las microempresas de servicios comerciales, de las multinacionales de la industria extractiva, la agricultura a baja escala, la pesca artesanal, el turismo y la administración pública (Bonet, 2007, pp. 31-45). Otra de las características de la población chocoana es no poseer cultura del pago de impuestos, por lo que la administración municipal adolece de suficientes recursos propios para la inversión y son altamente dependientes de las transferencias del Estado Nacional o del Sistema General de Participación SGP (Galvis, 2014) ${ }^{4}$.

En los municipios madereros y mineros del Chocó, la extracción del oro, platino, coltan, crudo y tala de bosques, son realizadas por empresas multinacionales, que aprovechan los bajos costos de la mano de obra local; dejando erosionado el subsuelo y al territorio más pobre en su organización social e institucional. Municipios donde

3 La violencia de Estado da cuenta del abandono que viven los municipios y las localidades al no existir gasto público de inversión en infraestructura que facilite el asentamiento empresarial y se generen nuevos empleos. Dichas ausencias de inversión ahondan en la pobreza que a su vez es causa de violencia intrafamiliar, ante carencia en bienes fundamentales básicos como el agua pura y el saneamiento ambiental. El noticiero RCN así lo informó el día sábado 17 de junio de 2017.

4 Lo que más llama la atención es la informalidad en el manejo de los registros contables y de archivo. Gran parte de la información sobre los ingresos corrientes no está actualizada; por ejemplo, en la cartera morosa del impuesto de Industria y Comercio aparecen comerciantes que ya no poseen negocio y no viven en la región. El recaudo del impuesto predial es bajo con problemas de sobre avalúos en predios rurales con baja producción agrícola. Las secretarías de Planeación creen que al menos el 30\% de dicha información contable es cierta. Incluso los archivos de información de la Alcaldía no están bien custodiados, por lo que existen problemas de verificación de predios en municipios, tales como Acandí, Codoto y Bahía Solano. 
se consolida: la prostitución, el vicio del licor y las economías subterráneas de la corrupción, narcotráfico y de grupos al margen de la ley.

De allí que, para hacer frente a la consolidación de la pobreza y violencia, las mujeres, se han agrupado a través de organizaciones sociales y comunitarias; siendo la Red Departamental de Mujeres Chocoanas, la de mayor poder de integración. Para lograrlo, la Red estudia la realidad que viven ellas en sus territorios, siendo una organización no gubernamental $\mathrm{ONG}$, que vela por el derecho de la mujer, presiona la implementación y puesta en marcha de políticas públicas de género laborales y de emprendimiento, con el apoyo internacional de las Naciones Unidas ONU, El Fondo de las Naciones Unidas para la Infancia - Unicef, Microempresas de Colombia y Fundación Aqua, las cuales contribuyen al mejoramiento, en servicios públicos de salud, educación e inclusión, como lo afirma el informe oficial de rendición pública de cuentas (Ruta Q, 2015) y la Red Departamental de Mujeres Chocoanas (2016).

Entre las estrategias seguidas por la Red Departamental de Mujeres, para salir del atraso social, político y económico en el que viven, están: Primero, aprovechar los diálogos de paz entre el Gobierno Nacional y los grupos guerrilleros para construir la propuesta multicultural de una Agenda de Paz de las Mujeres Chocoanas (2015), que sirva al diseño de políticas públicas de reparación de víctimas y no repetición de la violencia en la reconstrucción del tejido social de la nueva Chocó del posconflicto. Segundo, con el diseño de la Agenda de Paz, las mujeres chocoanas buscan visibilizar en el entorno nacional e internacional las necesidades del departamento, uno de los más victimizados por el conflicto armado, por más de cinco décadas. Tercero, combatir otros tipos de violencia existentes que impiden la reconstrucción del tejido social, tales como: violencia familiar, violencia por explotación sexual en municipios mineros y la violencia estatal, que se hace presente a través de la ausencia de hospitales, servicios públicos domiciliarios y sanitarios, universidades y privatización del territorio a empresas multinacionales. Violencias que afectan la dignidad y la convivencia ciudadana pacífica (Agenda de Paz de las Mujeres Chocoanas, 2015, pp. 11-16; Grupo Focal 13 de mayo de 2016, Red Departamental de Mujeres Chocoanas, 2016).

Una de las principales estrategias de la Red Departamental de Mujeres, para salir de la crisis social, política y económica que viven, es la de formar conciencia política en la comunidad de votantes, lo que limita el patriarcado político y ha facilitado el ascenso de las mujeres a las alcaldías de siete municipios de la región entre el 2012 y el 2016. Otra de las estrategias de la Red de Mujeres, para contrarrestar la violencia intrafamiliar y la violencia sexual, es la de haber logrado el liderazgo en cargos públicos de justicia, como: las fiscalías locales, seccionales y especializadas, las comisarías de familia e inspecciones de policía (Grupo Focal 15 de agosto de 2016, Cocomasur, 2016). De esta manera, la Red Departamental de Mujeres busca evitar el desgreño administrativo, la impunidad y la prescripción de procesos por pérdida de información (Entrevista personal, Morales 2017; Minota, 2016). 
Sobre estas dos estrategias de liderazgo femenino para ir saliendo de la crisis política, social y económica de sus territorios se pretende conocer cuáles fueron los resultados alcanzados en los municipios que gobiernan o gobernaron: Bahía Solano, Quibdó, Condoto y Acandí. De allí que, las preguntas de investigación sean: ¿qué tanto lograron las alcaldesas reducir la corrupción administrativa?, ¿qué hicieron ellas para reducir la violencia y reconstruir el tejido familiar dentro del hogar?, ¿qué progresos económicos lograron las líderes en emprendimiento y empleo?, ¿cómo lograron ellas restablecer la equidad de género dentro del municipio? En otras palabras, ¿qué tanto se ha beneficiado el municipio con el liderazgo gubernamental de ellas?

La metodología de investigación es cualitativa exploratoria a partir de información primaria, obtenida a través de entrevistas personales y grupos focales con miembros de la población, funcionarios públicos, líderes de organizaciones sociales y comunales y los planes de Desarrollo. La información recolectada por las fuentes primarias fue convalidada en cada uno de los cuatro municipios de estudio.

\section{Resultados del estudio en los municipios de Quibdó, Condoto, Acandí y Bahía Solano}

Con el fin de conocer las diferencias que perciben miembros de la población, funcionarios públicos, organizaciones sociales y comunales, al contar con un gobierno de alcaldesa en el municipio se preguntó:

\section{1. ¿Existe diferencia entre un gobierno público de mujer y uno de hombre?}

Para los habitantes del municipio de Condoto, sí ha existido diferencia, ya que ha sido una administración más consciente de las necesidades de la población más vulnerable, una administración con más inclusión al empleo; es decir, sin identidad política, con más atención a la población de la tercera edad e infantil y con menos patrocinio al consumo de licor entre los jóvenes. En otras palabras, con mayor apoyo social a las tareas de la mujer. Una administración pública con más conciencia social que económica. La actual administración se ha basado en el mérito de los profesionales de la función pública. La alcaldesa se ha rodeado de los buenos profesionales que tiene el municipio; lo que ha marcado la diferencia de la actual administración pública con las anteriores, como lo afirma (García, 2007, p. 41) con el fin de exigir responsabilidades (Entrevista personal, Gómez, 2017).

Es un gobierno que ha dado prioridad al trabajo agrario más que al minero, porque la explotación minera acaba con los recursos forestales; por el contrario, el trabajo agrícola produce el alimento y conserva la tierra para otros usos productivos. Conserva el arraigo y la identidad territorial como lo afirma (Stefanovic y Saavedra, 2016) en su informe sobre propuestas de política pública para la igualdad de género de la mujer minera en Chile. 
Sin embargo, la buena gestión de la alcaldesa se ha visto opacada por dos hechos fundamentales; primero, por la permanencia de actores armados al margen de la ley que son atraídos por la riqueza minera del municipio. Segundo, la prohibición estatal de la explotación minera artesanal y la sesión de derechos de explotación a empresas multinacionales, que acabaron con la principal actividad económica de la mujer de Condoto, el barequeo (Grupo Focal 15 de mayo de 2017, Agudelo, 2017) Pero, son realidades territoriales que vienen de muchos años atrás, como producto de los intereses económicos de los actores del conflicto armado y de la asociación público-privado que subasta los recursos naturales.

Para el representante de las Juntas de Acción Comunal en el municipio de Condoto, la administración pública de la mujer no establece diferencias con la del hombre. Ya que ambas han privilegiado a la población, sin establecer diferencias de género. Tanto el hombre como la mujer son tratados iguales (Entrevista personal, Mosquera, 2017).

En la ciudad capital del departamento del Chocó, líderes sociales afirman que sí hubo diferencia, ya que una líder fue capaz de competir con un gobierno familiar de más de 12 años; lo que ayudó a recuperar el territorio para todos sus moradores y sacarlo del atraso. Fue un gobierno de autoridad, porque cumplió con gran parte de ejecutorias -aeropuerto, pavimentación de vías, cines, biblioteca, parques, estación de policía y reducción de la violencia-. Lo negativo, afirman los líderes sociales, fue que no escapó al sobrecosto que dejaron sin recursos obras públicas fundamentales como el hospital, el colegio municipal y la vía Quibdó-Medellín (Entrevista personal, Álvarez, 2017). No fue capaz de neutralizar las presiones económicas de apoyo de las maquinarias políticas. Lo que contradice la hipótesis de eficiencia en la administración pública con la participación de la mujer de Lozano y Molina (2014); de manera real la corrupción no tiene género (Katzman y Rosa, 2016).

Para el municipio de Bahía Solano, coordinadores del programa Más Familias en Acción, afirman que el gobierno de la actual alcaldesa se ha distinguido porque ha tomado más en cuenta las capacidades de la mujer, al punto que en el desarrollo del programa de gobierno se exige que cada proyecto y cada obra que se ejecute en el municipio, debe contar con la participación femenina (Entrevista personal, Córdoba, 2017). Otra razón es, como afirma Muñoz (2014, pp. 202-3), porque la mujer imprime orden en el gobierno y más sentido de pertenencia en todo lo que se hace. Es un gobierno que busca la igualdad de trato en el desempeño de sus funcionarios. No es excluyente en el trato con la mujer, pero sí con el hombre, afirma el concejal (Entrevista personal, Bocanegra, 2017), se siente más presencia de la mujer en lo laboral y en lo administrativo público. El Concejo, por ejemplo, cuenta con 9 concejales de los cuales 4 son mujeres. Cambios que son nuevos y valiosos, pero que a veces se dejan sentir como un juego de rivalidad o de suma cero; es como si los derechos

$5 \quad$ El barequeo en el municipio de Condoto es fluvial, es la actividad por medio del cual las mujeres toman del río poncheras de arena rica en oro y platino, mediante el zarandeo separan el oro y el platino de los materiales impuros. 
de igualdad, protegieran más a las mujeres que a los hombres (Entrevista personal, Bocanegra, 2017).

\section{Para contrarrestar la violencia de género por falta de ingresos ¿qué programas viene realizando el municipio?}

Las familias del municipio de Condoto reciben las ayudas que envía el Gobierno Nacional mediante el programa Más Familias en Acción que ofrece ayudas en dinero y en mercados a núcleos familiares con niños entre los cero y siete años, para educación y alimentación, desde el año 2000. Si bien el programa es bueno, no logra el objetivo por dos razones; primero, porque, no se evalúa el cumplimiento de las metas, es decir, cuántas familias realmente salieron de su condición de vulnerabilidad; y segundo, porque aumenta la tasa de natalidad, ya que cada madre recibe ayuda en dinero por cada hijo menor de siete años. En otras palabras, no existe un seguimiento al uso eficiente de los recursos, Más familias en Acción es más un programa del clientelismo político electoral que de protección y fortalecimiento a la dignidad humana (Entrevista personal, Córdoba, 2017; Grupo Focal, Agudelo, 2017).

La administración municipal gestiona los recursos del SGP para saneamiento ambiental contratando jóvenes desempleados, para que limpien las fuentes hídricas así ellos no hayan votado por ella o no sean de su partido político; lo que hace de esta administración municipal una administración diferente (Grupo Focal, Agudelo, 2017). En otras palabras, la mujer, quizás por su condición de madre, es más solidaria, más consciente de las necesidades que hay en una casa (Muñoz, 2014, pp. 204-5).

En emprendimiento femenino, la administración municipal de la actual alcaldesa no ha hecho ningún avance, la mujer sigue dependiendo de los ingresos del esposo y realizando trabajos propios de la economía informal -ventas ambulantes, juegos de mesa y prostitución-. El barequeo desapareció del renglón económico por la llegada de las multinacionales. La mujer tiene pocas posibilidades de empleo o de valerse por sí misma, por tener bajos niveles de estudio, lo que la vuelve más dependiente del esposo (Grupo Focal, Agudelo, 2017). Afirmación que es corroborada por estudios de investigación de la CEPAL (Martínez, Miller, y Saad, 2013).

La Secretaría de Planeación y Obras Públicas del municipio de Condoto afirma, "si bien la alcaldesa se comprometió en la realización de proyectos que aporten a la equidad de género aún no se han comenzado a ejecutar; pero sí se está pensando en formular estrategias que impulsen el desarrollo creativo de la mujer cabeza de hogar" (Entrevista personal, Gómez, 2017). Para los Asocumunales, aún no existen programas oficiales enfocados a mejorar los ingresos de las mujeres en el municipio de Condoto. Los avances que se han dado en este campo, han nacido de la misma asociación de mujeres. Por ejemplo, la comunidad de mujeres creó el proyecto "Sembrando en tierra buena" en el que ellas intentan generar nuevas oportunidades de empleo, nuevas formas de generar recursos para el sostenimiento de la familia (En- 
trevista personal, Mosquera, 2017). En otras palabras, son el fruto de los esfuerzos de asociaciones civiles, y no de las políticas públicas del actual Gobierno.

El municipio de Condoto no tiene centros de formación técnica o universitaria. En otras palabras, adolece de buenos centros educativos y de investigación. En años anteriores el Servicio Nacional de Aprendizaje SENA capacitó en temas de estética y confección, pero el mercado se saturó; por lo que las mujeres cabeza de hogar se ven obligadas a dejar sus hijos con las abuelas para irse a buscar trabajo a otros departamentos (Entrevista personal, Mosquera, 2017). Recientemente, en el municipio de Condoto, se ha querido incentivar el estudio sobre el uso de plantas medicinales, como se viene haciendo en Quibdó, para ello se busca documentar el uso tradicional que hacían los abuelos de dichas plantas; pero para hacerlo empresa se necesita el apoyo institucional de universidades y centros de investigación (Entrevista personal, Mosquera, 2017).

En el municipio de Quibdó el emprendimiento no ha tenido buenos fundamentos. La mujer sigue laborando en el sector informal, debido a que el municipio adolece de infraestructura para el asentamiento de empresas. La mujer chocoana tiene la opción de ser licenciada y trabajar como maestra, o ser profesional en universidades de otros departamentos y quedarse trabajando allá, donde puede tener empleo y mejor salario (Entrevista personal, Álvarez, 2017). Las Juntas de Acción Comunal JAC tampoco impulsan el emprendimiento femenino porque adolecen de recursos propios. De igual manera, la administración actual ha descuidado lo alcanzado por el gobierno de la alcaldesa anterior en emprendimiento femenino.

El municipio de Bahía Solano sí ha logrado grandes avances. Con la Fundación Aqua, por ejemplo, se ha impulsado el programa "Azoteas Agrícolas", en las que cada familia cultiva y vende sus productos en casa, lo que les ayuda al cuidado del hogar. Además, a través de la Fundación Aqua se promueve la fabricación manual de artesanías y levante de pollos de engorde. Formas de emprendimiento que han mejorado los ingresos de las mujeres (Entrevista personal, Córdoba, 2017).

La administración municipal de Bahía Solano busca que la mujer se vuelva productiva, para ello ha estimulado desde la Oficina de la Mujer dos programas: "Solaneñas con Futuro" y "Mujeres de la Bahía". También se han apoyado en las capacitaciones de la comunidad europea Vasca en emprendimiento. Proceso que se ha dificultado por el carácter cultural de la mujer del municipio de no asociarse. La mujer del municipio de Bahía Solano gusta de ser liderada, no se atreven a tomar iniciativas de emprendimiento por sí solas, no son tomadoras de riesgo para ser empresarias, se desaniman muy rápido (Entrevista personal, Morales, 2017), y no es posible, en el presente siglo, hacer empresa sin asociarse. Sin embargo, un grupo de mujeres con la colaboración de la Secretaría de Salud, se vienen capacitando en los oficios de partera, con la Red de Parteras de Quibdó, ellas no cobran por la asistencia, pero sí reciben colaboración voluntaria por la prestación de sus servicios. Labor que hace parte de la 
solidaridad femenina ante la ausencia de hospitales, pero que también hace parte de las economías de regalo (Londoño, 2016).

De igual manera, en el municipio de Bahía Solano viene tomando fuerza el uso de plantas con fines comerciales y medicinales, para lo cual se están adecuando terrenos para el cultivo de dichas plantas, que van a ser procesadas y comercializadas en plazas del mercado local. Proceso que aún es artesanal porque adolece de investigación y del apoyo universitario (Entrevista personal, Mosquera; Morales, 2017). El municipio no cuenta con universidades cercanas ni con infraestructura apropiada para el asentamiento permanente; servicios públicos básicos de los que la Alcaldía incluso adolece. Carencias de infraestructura presente en los municipios de Acandí y Condoto, a pesar de sus densidades poblacionales (Galvis, 2014).

Las riquezas agrícolas productivas del municipio de Acandí, por ejemplo, se encuentran en manos de latifundistas, el 3\% de los productores concentran el 29,4\% del territorio y el $14,1 \%$ del territorio son de reserva natural; concentración del capital que dificulta el desarrollo por la poca diversidad productiva y escasas fuentes de empleo (PNUD, 2012, pp. 15-18). De allí, que el municipio cuente con una infraestructura casi inexistente en salud, educación, terrestre, marítima, zonas culturales y productivas; lo que ahonda en la pobreza, en las violencias de Estado y de género (PNUD, 2012, p. 19).

El programa de Gobierno de la alcaldesa se enfoca principalmente en la salud, dada la ausencia de hospitales y la escaza infraestructura de comunicación que aíslan al municipio por vías terrestres y marítimas. Los programas banderas son: "Madres con corazón de leche", para las buenas prácticas materno-preventivas y el programa "Acandí piensa y actúa", para la salud sexual y reproductiva. Ante las pocas fuentes de diversión para los jóvenes el consumo del licor y el sexo se convierten en el principal pasatiempo, lo que les lleva a perder oportunidades de superación, autorrealización y de libertad. Violencia de Estado que se traduce en violencias de género; más del 70\% de las mujeres son cabeza de hogar (Grupo Focal, Cocomasur, 2016; Plan de Desarrollo del Municipio de Acandí 2016-2019).

\section{3. ¿Qué se viene haciendo en el municipio para el control de la violencia de género?}

En el municipio de Condoto, afirman mujeres víctimas de la violencia, que a pesar de haber en la alcaldía una mujer, no se ha hecho nada para contrarrestar la violencia de género; por el contrario, se viene agravando con amenazas de muerte (Grupo Focal, Agudelo, 2017). Condoto es un municipio en el que todos los habitantes se conocen, de allí que la policía es, por lo general, amiga del agresor. Los dirigentes de la Casa de Justicia y Paz son familiares o son amigos, y si son desconocidos, la solidaridad masculina, las invitaciones y las dadivas los hace conocidos (Grupo Focal, Agudelo, 2017). 
Tampoco se ha avanzado en la educación del niño para el amor y el respeto a la mujer. Culturalmente el hombre del departamento del Chocó es machista, promiscuo y de trato fuerte con la mujer (Grupo Focal, Agudelo, 2017).

En los municipios de Condoto y Quibdó el maltrato de género es condenado por las mismas organizaciones civiles de las mujeres, a través de las redes sociales. El envío por WhatsApp de fotos, videos, conversaciones de maltrato o de feminicidios provoca la solidaridad y la movilización ciudadana por las calles del pueblo; presionan al Gobierno e incluso han hecho renunciar del cargo a funcionarios públicos (Entrevista personal, Mosquera, 2017; Álvarez, 2017).

La mejor manera de acabar con dichas prácticas culturales de violencia de género es educando a la mujer y al niño en el amor propio, en el amor natural, a sí mismos, en el autocuidado desde las escuelas (Grupo Focal, Agudelo, 2017). En el municipio de Condoto, lo único que se podría sumar como inversión social contra la violencia de género es la construcción de cuatro parques al aire libre para el esparcimiento familiar, aunque ellos adolecen de programas públicos de acompañamiento y de orientación al fortalecimiento de las familias (Grupo Focal, Agudelo, 2017).

Para las JAC la alcaldesa del municipio de Condoto sí ha dado atención a la reducción de la violencia intrafamiliar y reconstrucción del tejido social. El trato del hombre chocoano a la mujer siempre ha sido fuerte, sin embargo las escuelas están implementando programas de educación infantil para la no violencia, tales como: "Manbrú no va a la guerra", en el que se abordan temas sobre la no violencia de género. La violencia de género aún es pan de cada día, para erradicarla se necesitan años de trabajo continuo. Lo importante es que la administración municipal ya comenzó (Entrevista personal, Mosquera, 2017).

En el municipio de Quibdó los líderes sociales afirman que una de las grandes ventajas de la alcaldesa anterior, es que venía de ser miembro de las JAC, por lo que conocía muy bien la problemática de género. Durante el gobierno pasado, la alcaldesa logró dos grandes proyectos para la construcción del tejido social familiar. Primero, diseñó y escaló a nivel nacional una política pública para la mujer negra e indígena del municipio. Segundo, creó la Secretaría de la Mujer, ubicando en dicho cargo a una persona competente, una mujer que había trabajado con Profamilia; dicha funcionaria fue ratificada en el cargo. De igual manera, la alcaldesa logró consolidar ayuda internacional con la ONU en programas de capacitación en la defensa de los derechos de la mujer y del valor de la familia con Unicef (Entrevista personal, Álvarez, 2017).

Parte del trabajo dejado por la alcaldesa en beneficio de la mujer no ha tenido continuidad por el alcalde actual; los programas de emprendimiento, por ejemplo, perdieron impulso (Entrevista personal, Álvarez, 2017). Las políticas de empoderamiento de la mujer, de amor propio, de responsabilidad del padre con los hijos, de reducción de embarazos a temprana edad o de sexo responsable, perdieron continuidad con el cambio de administración; todo el trabajo de transformación cultural se 
perdió, con la culminación del gobierno de la alcaldesa en el 2016 (Entrevista personal, Álvarez, 2017).

En el municipio de Bahía Solano, el Instituto Colombiano de Bienestar Familiar ICBF y la Comisaría de Familia han ejecutado campañas para prohibir el maltrato femenino, aún incluso el psicológico. Se capacita a la mujer en la importancia de denunciar a tiempo, de ser firme al momento de denunciar, para que no se sigan presentando tales abusos. Cuando se presenta una denuncia, se deja un registro que sirve de control y de sanción en caso de reincidencia. Mecanismos que han tenido muy buenos resultados (Londoño, 2016).

Otra de las acciones seguidas por la administración es emplear a mujeres en la recepción de quejas, porque ellas pueden manifestar más fácilmente la intimidad de dichos abusos a otra mujer, que a un hombre, lo que facilita el diálogo y la confianza, como lo afirma el Instituto Andaluz de la Mujer (2016) en España. Incluso, la mujer puede ser más prudente en el proceso de llamado de atención al victimario, de tal manera que no se provoque rompimientos de lazos familiares. Es decir, no se ahonde aún más en el problema (Entrevista personal, Córdoba, 2017).

Por medio de talleres de familia y de empoderamiento de la mujer, se busca corregir conductas de comportamiento, tanto en la responsabilidad de los padres con sus hijos como en el fortalecimiento del amor propio (Entrevista personal, Morales, 2017; Instituto Andaluz de la Mujer, 2016). Se enseña a la mujer víctima de la violencia, al buen trato con sus hijos, incluso a las adolescentes desde los 11 años que son madres y a las que son cabeza de hogar, a través de la Mesa de Equidad de Género. De igual manera, se enseña el sexo responsable en escuelas y colegios; además, las administraciones municipales en coordinación con el hospital brindan capacitación en responsabilidad sexual y reproductiva y dan sin costo preservativos en la semana de las fiestas patronales, con el fin de reducir el número de embarazos (Entrevista personal, Córdoba, 2017; Morales, 2017).

En el municipio de Acandí solo existe un banco que está en la cabecera municipal y ofrece microcréditos para el emprendimiento, principalmente en el cultivo de cacao y tenencia de ganado. El banco no presta para fortalecimiento turístico, según el Programa de las Naciones Unidas para el Desarrollo PNUD, por encontrarse el municipio en zona de conflicto armado (PNUD, 2012, p. 27; Grupo Focal, Cocomasur, 2016).

\section{4. ¿Qué ha hecho la alcaldía de la mujer para reducir la violencia de Estado?}

En municipios pobres como los del departamento del Chocó se adolece de infraestructura para el desarrollo económico, como: vías para el transporte interno e interdepartamental de mercancías, instituciones de educación superior que estudien el aprovechamiento de los recursos para la producción de bienes exportables; en otras palabras, que impulsen el asentamiento de industrias manufactureras y generen nuevos empleos, como ya lo afirmara Sanders Thomas (Sanders, 1970). La ausencia de 
apoyo a la inversión pública genera más pobreza, y por ende más violencia estatal, es decir, más descomposición social y de las familias por falta de oportunidades. La violencia de Estado también incluye la corrupción política, porque la política es la principal fuente de la politización del empleo y de rompimiento de las normas de seguridad social en la contratación laboral; porque es causa de atraso y cambio de valores sociales, máxime cuando es ejercida por mandatarios de la misma región (Muñoz, 2014, p. 205; Ortiz, 2014).

En el municipio de Condoto, no se está haciendo "nada", afirman mujeres víctimas de la violencia intrafamiliar:

Aunque parece extraño, la administración municipal no paga a los médicos, razón por lo cual ellos no volvieron al municipio. Los enfermos son remitidos a otros municipios cercanos. La casa de tres pisos que la alcaldía asignó a la Unicef, Cruz Roja y Visión Mundial para atender problemas de salud fue suspendida a estos organismos internacionales, y es hoy usada por los jóvenes como centro para el consumo y expendio de drogas ilícitas (Grupo Focal, Agudelo, 2017).

La ausencia de un hospital atenta con la equidad de género, porque quien atiende a los enfermos en el hogar es la mujer. La mujer del municipio de Condoto no tiene posibilidades de estudio, porque desde los 11 años es victimizada por el minero, un familiar, el profesor o un amigo que la embaraza y la deja sola, o por la pobreza del hogar, lo que la obliga a ser empleada doméstica, de casinos o juegos de mesa o a la prostitución (Grupo Focal, Agudelo, 2017).

Para los representantes de la asociación municipal de Juntas de Acción Comunal se ha venido mejorando el estado de las vías y de los parques públicos, pero el municipio no se ha adecuado a la inversión empresarial. Incluso, se adolece de proyectos, en otras palabras, no hay norte (Entrevista personal, Mosquera, 2017).

En el último año se han construido diques, en asociación público-privada, para evitar el desbordamiento del río en épocas de lluvia. Los pagos realizados a la alcaldía por la entidad privada, por materiales extraídos de la orilla del río en la construcción del dique, serán devueltos en inversión social para el municipio. Sin embargo, la alcaldía no ha rendido aún informes. Las JAC y los habitantes esperan el informe financiero y la asignación de los recursos (Entrevista personal, Mosquera, 2017).

Los proyectos y gastos para el sostenimiento, incluso los de baja cuantía, son entregados a contratistas, no a las JAC, no se empodera al ciudadano común por su comunidad. Contratos que alimentan a las maquinarias políticas y agotan más rápido los recursos disponibles (Entrevista personal, Mosquera, 2017; Ortiz, 2014). Los contratos de limpieza de calles o del río deberían darse a las JAC por norma, lo que fortalece a las organizaciones comunales y comunidades que representan. Pero, no ocurre así. Estas contrataciones son entregadas a grandes empresas que benefician económicamente a los contratantes (Entrevista personal, Mosquera, 2017). 
La Secretaría de Desarrollo del municipio de Condoto convoca a los dirigentes comunales cuando van a entregar beneficios o donaciones que llegan de otros municipios de Colombia para los habitantes, pero no convocan a las JAC para que participen de los proyectos de desarrollo que demanda la comunidad; lo que reduciría los sobrecostos por pagos de intermediación y beneficiaría a la comunidad con más recursos disponibles (Entrevista personal, Mosquera, 2017).

En el municipio de Bahía Solano, lo único que se está haciendo es construir un hospital de tercer nivel y fortalecer convenios de educación con universidades de otros departamentos; para ello es necesario lograr consensos con alcaldías de otros municipios cercanos, los cuales se muestran poco colaboradores por realizarse las obras en Bahía Solano y no en el municipio de ellos. En otras palabras, no se trabaja como un área metropolitana que integra a todas las poblaciones en beneficio común (Entrevista personal, Córdoba, 2017; Morales, 2017). Si los municipios se integran, se facilita la inversión, por haber mayor demanda poblacional, lo que genera economías de escala. "Si los gobiernos de los demás municipios cercanos fueran mujeres, ya se hubiese construido el hospital de tercer nivel que tanto necesitamos. Se preferiría el bienestar social al beneficio particular de los partidos políticos" (Entrevista personal, Morales, 2017).

\section{5. ¿Qué razones explican la pobreza en el municipio y qué relación puede tener ella con la violencia intrafamiliar?}

Para la Asociación Municipal de Juntas de Acción Comunal del municipio de Condoto "Si usted no tiene qué comer y qué darle a sus hijos, usted hace lo que sea para llevar el pan a la mesa". Cuando un administrador público entiende esa necesidad natural de la gente y diseña verdaderas políticas productivas para la reducción del desempleo, reduce la violencia (Entrevista personal, Mosquera, 2017). Se necesita de proyectos macro, que estimulen el empleo, necesita de una gerencia pública que estimule y apoye la inversión privada y preserve el bien común de todos los recursos, como afirma Slavoj:

Lo que todas las luchas para defender bienes comunes comparten, es la conciencia del potencial destructivo que podría liberarse, si se permite que la lógica de las privatizaciones de los bienes comunes campe a sus anchas, quizá hasta el punto de la autodestrucción de la propia humanidad (Žižek, 2016, p. 120).

Además, conservar su identidad cultural desde su población infantil, de allí que los proyectos como "Mambrú no va a la guerra" y "Sembrando en tierra buena", enseñan al niño a ser solidario con el otro y a ser emprendedor, conservando su identidad cultural de ser humano (Entrevista personal, Mosquera, 2017).

En reunión sobre los consejos comunitarios celebrado con la Mesa Minera de los municipios de Acandi, Quibdó, Condoto y la Gobernación del Chocó en la Institución Educativa María Auxiliadora, la Asociación de las Juntas de Acción Comunal, preguntó: ¿dónde están los porcentajes que las empresas mineras entregan a ustedes 
por el derecho de explotación dentro de sus comunidades?, ¿dónde están los porcentajes por permiso de explotación que los mineros entregan a ustedes por el oro que extraen?, ¿en qué lo invierten?, ¿dónde está ese dinero que se extrae de los recursos comunes y debe compensar a la comunidad? Preguntas que no tuvieron respuestas, pero si justificaciones políticas.

Los consejos comunitarios son autónomos, pero quién los regula, por qué dichos organismos no participan con el presupuesto de inversión social que debería manejar la administración municipal. Dichas organizaciones deberían acabarse y ser investigadas, ya que se han apropiado de recursos comunes de la comunidad, algunos de ellos son dueños de entables mineros (Entrevista personal, Mosquera, 2017). Si bien la ley ha cambiado y entrega la autoridad para celebrar contratos con multinacionales de la industria extractiva a la alcaldía, el vacío de la ley es con los permisos de explotación que fueron otorgados antes de la nueva vigencia, Ley 1833 de 2017, la cual protege recursos y derechos colectivos e individuales de las comunidades negras para el mejoramiento de sus condiciones y de calidad de vida.

Eso es lo que hace al municipio de Condoto y al departamento del Chocó pobres; la falta de voluntad política para trabajar en bien de la comunidad y no de las maquinarias políticas dueñas de la corrupción pública, las coimas, las bonificaciones o beneficios económicos privados por patrocinar, ayudar o asignar derechos de explotación (Ortiz, 2014). Por eso, el Gobierno Nacional designó a un ingeniero del Chocó en el Ministerio del Medio Ambiente, porque es conocedor de los potenciales mineros que existen en la región, lo que facilita la entrega de concesiones mineras del Gobierno a multinacionales (Entrevista personal, Mosquera, 2017).

La falta de proyectos de inversión y la ausencia de proyectos para el desarrollo no ha permitido que el municipio pueda utilizar los recursos que le llegan del Gobierno Nacional por regalías. Al día de hoy, tienen represados más de 4.000 millones de pesos (Entrevista personal, Mosquera, 2017).

La ausencia ciudadana de responsabilidad política. En los municipios de Condoto, Quibdó y en general en todo el departamento del Chocó se negocian votos que van desde los \$200.000 a los \$800.000. La gente elige al que mejor paga el voto, ese es el problema del atraso y del desempleo. Los políticos son los dueños de una empresa electoral que les permite apropiarse del municipio, de sus recursos y de sus habitantes, elección tras elección (Grupo Focal, Agudelo, 2017).

La pobreza en el municipio de Quibdó puede ser explicada por la falta de liderazgo de las JAC, los líderes son elegidos sin el conocimiento y capacidades de liderazgo para el trabajo social. Ellos llegan al cargo por las rencillas políticas (Entrevista personal, Álvarez, 2017). La falta de un verdadero liderazgo capaz de brindar solución a los problemas de las comunidades, imposibilita la construcción de las agendas locales, que sirvan a los programas de gobierno y posteriormente a los planes de desarrollo local y territorial de los candidatos electos. 
Otro de los problemas que afecta al municipio de Quibdó es la corrupción pública, a través de la ejecución de obras viales, por ejemplo, se pierden grandes sumas de dinero público; lo que deja incomunicado al municipio y al departamento (Entrevista personal, Álvarez, 2017; Ortiz, 2014). En otras palabras, deja al municipio sin infraestructura de comunicación, sin posibilidades de establecer polos de desarrollo industrial y de empleo. Su presupuesto es de casi 200 mil millones de pesos por el SGP, inversión que no se ve, en los hospitales, educación y saneamiento ambiental; nada avanza, todo sigue empeorando (Entrevista personal, Álvarez, 2017). También ocurre lo mismo en el departamento, ¿en qué se invierten los 800 mil millones de pesos que recibe de la nación? No se ven obras que impacten el desarrollo del Chocó (Entrevista personal, Álvarez, 2017), ver además (Ortiz, 2014).

Antes de 1930 el departamento fue pujante, tenía fábricas de velas y de aguardiente, lotería, azúcar y gaseosas, ahora no cuenta con esas empresas, todas se han quebrado y con ellas sus 30 municipios. El departamento del Chocó no debe pedir al Gobierno las donaciones propias de las economías del regalo, por el contrario, lo que debe solicitar es ayudas financieras para recuperar la industria y generar empleo (Entrevista personal, Álvarez, 2017). No es con estas economías de regalo, como afirma (Mill, 1834, p. 361), que un municipio y un departamento salen del atraso económico, por el contrario, más se empobrecen, es con inversión en infraestructura. Las fábricas generan trabajo e impuestos que ayudan a financiar el gasto público en salud, educación e investigación.

El municipio de Quibdó, al igual que el de Acandi, Condoto y Bahía Solano, no poseen salas de cine, ni buenas placas deportivas, ni suficientes sitios de recreación, por lo que las personas se divierten consumiendo licor. Hechos que empobrecen aún más al departamento, porque acaba con su capital más valioso, la gente (Entrevista personal, Álvarez, 2017). El departamento del Chocó no debe vivir solo del dinero que le envía la Nación, debe crear empresas para dignificar a su gente y brindarles bienestar. Generar sus recursos fiscales de funcionamiento y de inversión en materia fiscal (Muñoz, 2009, p. 35; 2017).

En el municipio de Quibdó, a pesar de la buena gestión de la alcaldesa anterior, se quiso replicar lo mismo, llevando a otra mujer a la gobernación, pero los partidos políticos rivales, para no dejarla subir, por ser mujer y quitarle el liderazgo, se unieron para repartirse la ganancia política (Entrevista personal, Álvarez, 2017). Las maquinarias políticas y los malos gobiernos son el mayor atraso para el departamento. No es el hecho de ser afrodescendiente, sino el querer seguir viviendo de las donaciones y de los escasos recursos fiscales propios, lo que facilita el clientelismo, es decir, la concentración del poder político y económico de las maquinarias políticas (Entrevista personal, Morales, 2017).

En el municipio de Bahía Solano, el atraso administrativo viene de administraciones pasadas, en las que no se hizo un análisis de las causas del atraso para corregirlas. No ha habido orden administrativo para consolidar el desarrollo y se ha facilitado la 
proliferación y asentamiento de actividades ilícitas, como el narcotráfico (Entrevista personal, Morales, 2017; Saavedra, 2017, pp. 62-65).

Enseñar al niño a ser emprendedor, a ganarse la vida con el trabajo honrado, enseñarles el valor del dinero ganado con esfuerzo propio, a ser responsable con su bienestar y el de los demás; esa educación es lo que municipios como Bahía Solano deben inculcarles, para detener el flagelo del narcotráfico y el cambio de valores morales en los jóvenes (Entrevista personal, Morales, 2017).

Una de las causas más apremiantes del atraso en el municipio de Bahía Solano es el cambio de los valores del trabajo. La economía del regalo vuelve al ser humano atenido y conformista, de allí la importancia que tiene para la administración actual el valor del trabajo, de la honestidad y del amor natural a sí mismos en mujeres y niños (Entrevista personal, Morales, 2017; Žižek, 2016, p. 99). Para lograrlo, es necesario derrocar el fantasma de la economía ilegal del narcotráfico, como dice Saavedra, del mágico polvo blanco que todo lo compra rápidamente -mujeres, licor, alimento, ropa y tecnología- (Saavedra, 2017, pp. 50-52), ese facilismo de la ilegalidad que acaba con lo más preciado de los territorios, sus jóvenes.

\section{Conclusiones}

Para saber si es mejor el gobierno público de la mujer o del hombre en las comunidades negras del departamento del Chocó, es necesario más tiempo de observación, por lo menos tres períodos electorales más de alcaldías de la mujer en un mismo municipio (Entrevista personal, Morales, 2017). Sin embargo, puede afirmarse que sí se ha logrado mejorar en la equidad de género, en el control a la violencia de género, en la conciencia política o de la reconstrucción del bien común de la cultura, al dársele más protección a la mujer. Si se protege la mujer se protege al niño y la familia, máxime en un territorio donde el 70\% de las mujeres son cabeza de hogar, es decir, son formadoras de futuros ciudadanos.

Las líderes de los diferentes municipios del Chocó ven el atraso como consecuencia de deficientes administraciones municipales anteriores, por cuanto no se proyectó el territorio al crecimiento y al desarrollo económico (Entrevista personal, Morales, 2017), generando sus propios recursos fiscales (Entrevista personal, Álvarez, 2017). Para las líderes políticas, la economía del regalo es causa del atraso, pues es muy adictiva y peligrosa en la formación del carácter del ser humano, ya que lo vuelve conformista, le cercena su valor más preciado: la dignidad (Entrevista personal, Morales, 2017).

Los líderes, por el contrario, creen que el atraso socioeconómico de los municipios del Chocó obedece a que son afrodescendientes y fueron esclavos. Consideran que la sociedad les sigue mirando como tal, después de más de 200 años (Grupo Focal, Cocomasur, 2016; Muñoz, 2017). 
Miramientos que buscan justificar la pobreza, desde el color de piel, que no son tan ciertos. Sin embargo, dichas afirmaciones trascienden en algunos sectores de la población organizada, que se prestan para demandar jurídica y legalmente, a través de sanciones económicas a poblaciones e instituciones de mayoría mestiza y blanca; lo que se ha llegado a convertir en fuente privada de ingresos. ¿Cómo evitar las rivalidades del atraso económico? ¿Cómo ponerle fin al clientelismo político y a las estructuras de las microempresas electorales, que alimentan egoísmos y corrupción? Para lograrlo, es necesario rescatar la importancia de los programas de Gobierno, haciendo que ellos primen sobre la imagen política del candidato, o del aval político de las maquinarias.

No son las microempresas electorales, ni la competencia demagógica de los candidatos a una colegiatura, ni las promesas futuras de contratos laborales, lo que debe definir unas elecciones políticas democráticas. Por el contrario, lo que debe primar en las contiendas políticas es el estudio a conciencia, por parte de un grupo de tecnócratas o de expertos, sobre la viabilidad de los proyectos o planes presentados por los aspirantes a cargos públicos y luego ser presentados a la comunidad, para que los conozca y los discuta; para que sea la comunidad la que decida cuáles son los proyectos de Gobierno que se comprometen a trabajar y a respaldar, porque se ven representadas. La comunidad deberá preguntarse: ¿cuál es el mejor programa de Gobierno?, ¿cómo nos imaginamos el territorio en cuatro o cinco años? Una vez los diferentes programas son ampliamente conocidos por la comunidad, los proponentes serán dados a conocer. Dando así inicio a la campaña política electoral (Muñoz, 2014, pp. 97-98). Los ganadores de la contienda electoral serán los encargados de liderar la ejecución de los proyectos aprobados en el Plan de Desarrollo. La sociedad se convertirá entonces en sus contratantes, será la veedora y fiscalizadora del debido cumplimiento.

La anterior propuesta amerita la investigación sobre un nuevo diseño en logística social, con fines electorales. Una nueva forma de ver y entender el arte de hacer política, como promotora del desarrollo social. Una acción social comunicativa ${ }^{6}$ donde los hechos son más importantes que las palabras. Una democracia para la felicidad social, y no para el clientelismo y la demagogia. Como afirma el docente William Cerón González (2014) en la portada del libro "Democracia o Engaño": "La educación debe asumir el asunto de la democracia como punto de partida y referente en la formación del ciudadano, haciendo de ella un proyecto de inclusión que supere el procedimiento del sufragio". Lo que hará de la democracia un bien de inclusión social imprescindible; en la que los ediles y cabildantes, trabajan por el bien de todos y no del exclusivo beneficio propio. En otras palabras, se logra un efectivo control po-

6 La acción social comunicativa es una de las bases que estableciera el filósofo alemán Jürgen Habermas para estructurar su postura crítica sobre la modernidad. Él observa cómo la interacción social del ser humano pasa de basarse en ritos a la potencia del signo lingüístico, con la fuerza racional de las verdades sometidas a crítica. Las estructuras de acción comunicativa orientadas a un acuerdo se vuelven cada vez más efectivas, tanto en la reproducción cultural como en la interacción social o en la formación de la personalidad (Habermas, 1987). 
lítico, de las inversiones sociales y del presupuesto. Se hace de la política una virtud y no un vicio. Se fortalece el tejido de la gran malla social.

\section{Referencias}

Acemoglu, D., \& Robinson, J.A. (2012). Por qué fracasan los países. Los orígenes del poder, la prosperidad y la pobreza. (2a . ed.). Colombia. Deusto.

Acuerdo 011. (2013). Por medio del cual se adopta la Política Pública de Equidad de Género, con enfoque diferencial para las mujeres. Consejo Municipal de Quibdó: Alcaldía de Quibdó.

Agenda de Paz de las Mujeres Chocoanas. (2015). Quibdó: Red Departamental de Mujeres Chocoanas.

Agudelo, M. (2017). Grupo Focal, Hotel la Soberana. Reunión con mujeres víctimas de violencia del municipio de Condoto.

Álvarez, R.J. (2017). Entrevista personal, líder social, municipio de Quibdó.

Bocanegra, P. (2017). Entrevista personal, concejal del municipio de Bahía Solano.

Bonet, Jaime. (2007). ¿Por qué es pobre el Chocó? Cartagena: Banco de la República Centro de Estudios Económicos Regionales, CEER. Documentos de trabajo sobre economía regional, número 90.

Cerón, G.W. (2014). Democracia o engaño. Medellín: Universidad Autónoma Latinoamericana, Ediciones UNAULA.

Consejo Comunitario de Comunidades Negras Cocomasur. (2016). Grupo Focal, Políticas Públicas de la Equidad de Género para la Mujer Chocoana. Acandí, Colombia.

Córdoba, M.A. (2017). Entrevista personal, Secretaría de Desarrollo de la Mujer, Más Familias en Acción, Municipio de Bahía Solano.

García, S. I. (2007). La nueva gestión pública: evolución y tendencias, Universidad Salamanca, Revista Presupuesto y Gasto Público, 47, 37-64.

Galvis, L. A. (2014). Eficiencia en el uso de los recursos del SGP: los casos de la salud y la educación. Cartagena: Banco de la República, Centro de Estudios Económicos Regionales, CEER. Documentos de trabajo sobre economía regional, Número 207.

Gómez. M. E. (2017). Entrevista personal. Secretaria de Planeación, Municipio de Condoto.

Habermas. J. (1987). Teoría de la acción comunicativa. Madrid, España: Taurus. 
Instituto Andaluz de la Mujer. (2016) ¿Cuáles son las funciones de las abogados y procuradoras designadas que se han designado de oficio? España: Junta de Andalucía. Ante la violencia de género una única voz.

Katzman, J., y Roza, V. (2016) ¿La corrupción tiene género? Si ponemos la vara ética para las mujeres dirigentes más alta que para los hombres, ¿no las estamos condenando a un potencial fracaso? Diario El País, 04 de marzo de 2016, Opinión. Artículo del Banco Interamericano de Desarrollo BID.

Londoño, L. (Comp.). (2016). Equidad de género una perspectiva de desarrollo incluyente para mujeres y hombres. Bahía Solano, Chocó. Proyecto: "Empoderamiento de mujeres vulnerables en la costa Pacífica colombiana. Microempresas de Colombia y la Agencia Vasca de Cooperación para el Desarrollo.

Lozano, C., y Molina, E. (2014). La ley de cuotas como mecanismo eficiente en la participación política de las mujeres. Justicia Juris, 10 (2), 83-94.

Martínez, C., Miller, T., y Saad, P. (2013). Participación laboral femenina y bono de género en América Latina. Documento de Proyectos No 570: Chile: CEPAL/ IDRC, ONU.

Mill, J.S. (1834). The Proposed Reform of the Poor Law Amendment Bill. Monthly Repository, vol. 7.

Mill, J.S. (2005). El sometimiento de las mujeres. Prólogo por Ana de Miguel. Madrid: Biblioteca Edaf.

Minota, I. (2016). Entrevista personal. Políticas públicas de la equidad de género para la mujer chocoana. Quibdó, Colombia.

Morales, E.J. (2017). Entrevista personal. Secretaría de la Mujer de Bahía Solano. Políticas públicas de la equidad de género para la mujer chocoana. Alcaldía de Bahía Solano.

Mosquera, W. (2017). Entrevista personal. Presidente de la Asociación de Juntas de Acción Comunal, municipio de Condoto.

Muñoz, Á. E. (2017). Políticas públicas de dignidad de género para la mujer negra colombiana. Inciso, 19 (2), 53-65.

Muñoz, Á.E. (2017). Valores públicos y bienes públicos. Conferencia a concejales del municipio de Bahía Solano. Concejo de Bahía Solano.

Muñoz, Á.E. (2014). Gender Dignity in the Colombian Labor Market (2000-2013). Scientific Research an Academic Publisher, 4 (4), 195-207.

Muñoz, Á.E. (2009). Macroeconomía y desarrollo. Medellín: Ude@ Facultad de Ingeniería, Universidad de Antioquia. 
Ortiz, U. (2014). Chocó: entre riqueza, corrupción y olvido. Bogotá: Revista Semana: Casa Editorial el Tiempo, Opinión.

Plan de Desarrollo Municipio de Acandí 2016-2019. Equidad, transparencia y solución. Alcaldía de Acandí, Chocó, Secretaría de Planeación.

PNUD. (2012). Perfil productivo municipio de Acandí-Chocó. Programa de las Naciones Unidas para el Desarrollo: Red Ormet.

Red Departamental de Mujeres Chocoanas. (2016). Grupo focal. Políticas públicas de la equidad de género para la mujer chocoana. Quibdó, Colombia Ruta Q... ¡Una tarea bien hecha! (2015). Informe de gestión (2012-2015). Quibdó: Alcaldía de Quibdó.

Saavedra, B.D. (2017). Mi perdición. Un mundo sin salida. Quibdó, Bahía SolanoColombia.

Sanders, T. G. (1970). Los negros del Chocó. Fieldstaff Reports: West Coast South America Series, XVII(2).

Stefanovic, A., y Saavedra, M. (2016). La mujer en el sector minero de Chile. Propuestas para políticas públicas de igualdad. Naciones Unidas, CEPAL: Corporación Alemana.

Žižek, S. (2016). La nueva lucha de clases, los refugiados y el terror. Barcelona: Anagrama. 